Research Article

\title{
Comparison of the effects of amlodipine and cilnidipine on blood pressure, heart rate, proteinuria and lipid profile in hypertensive patients
}

\author{
Zaki A. Zaman*, Vishnu Kumari
}

Department of Pharmacology, Shri Krishna Medical College, Muzaffarpur, India

Received: 9 January 2013 Accepted: 27 January 2013

\section{*Correspondence to:}

Dr. Zaki A. Zaman,

Email:

zamanzakianwar@yahoo.co.in

C) 2013 Zaman ZA et al. This is an open-access article distributed under the terms of the Creative Commons Attribution License, which permits unrestricted use, distribution, and reproduction in any medium, provided the original work is properly cited.

\begin{abstract}
Background: Hypertension is a widespread public health problem and a major risk factor. Amlodipine, a calcium channel blocker is frequently used in the treatment of hypertension. Since Amlodipine primarily L-type calcium channel blocker (CCB) and thus reduces blood pressure, it stimulates sympathetic nerve activity leading to reflex increase in heart rate. Cilnidipine, a new type of CCB which can inhibit L- type calcium channels but also N-type calcium channels. We compare the clinical effectiveness of Amlodipine and Cilnidipine on blood pressure, heart rate, proteinuria and lipid profile in hypertensive patients.

Methods: The study was a prospective, randomized, open label comparison, total ninety five patients were recruited for study in which 45 patients received 5-10mg Amlodipine and other 55 patients of same age groups received 1020mg Cilnidipine. 15 patients in Amlodipine group and 18 patients in Cilnidipine group were diabetic, whereas 12 and 14 patients were proteinuric in Amlodipine and Cilnidipine group respectively.

Results: Both the groups were well matched in term of age, weight, clinical findings and laboratory values. Both the drug significantly reduced both systolic (SBP) and diastolic blood pressure (DSP). In the Amlodipine group the pulse rate (PR) after treatment tended to be higher than those before treatment. In the Cilnidipine group there was decrease in PR after treatment. Unlike Amlodipine, Cilnidipine decreased urinary protein excretion and in diabetic patients reduced serum triglyceride.

Conclusions: The study indicates that unlike Amlodipine, Cilnidipine which inhibits L-and N-type calcium channels will be useful for patients with hypertension and cardiovascular disease, diabetes mellitus or renal disease and proves to be a better alternative to existing calcium channel blockers.
\end{abstract}

Keywords: Hypertension, Cilnidipine, Amlodipine, Diabetic, Proteinuric

\section{INTRODUCTION}

Hypertension is a widespread public health problem and a major risk factor. ${ }^{1}$ It may lead to damage of heart, kidney, brain, vasculature and other organs results in premature morbidity and death. ${ }^{2}$ Cilnidipine is a novel and unique 1,4-dihydropyridine derivatives calcium antagonist with potent inhibitory action against not only L-type but also $\mathrm{N}$-type voltage-dependent calcium channels. ${ }^{3}$ The $\mathrm{N}$ type voltage-dependent calcium channel plays an important role in sympathetic neurotransmission and regulates the release of norepinephrine from sympathetic nerve ending. ${ }^{4}$ It has been reported that once daily administration of Cilnidipine resulted in a safe and more effective BP decrease in essential hypertension without excessive BP reduction or reflex tachycardia than similar administration of other dihydropyridine calcium antagonist. $^{5}$ Akira Takara $^{6}$ showed that plasma norepinephrine concentration, a sensitive marker of sympathetic nerve activity, is a significant prognostic marker of mortality in congestive heart failure patients. De Champlain ${ }^{7}$ showed a sustained rise in blood norepinephrine levels by more than $50 \%$ after chronic therapy of Amlodipine. The inhibitory effect on the Ntype $\mathrm{Ca}^{2^{+}}$channel by Cilnidipine may bestow an additional clinical advantage for the treatment of hypertension, such as suppression of reflex tachycardia. ${ }^{8}$ 
In morning, arousal from sleep is associated with rise in plasma epinephrine. Cilnidipine due to its sympathetic inhibitory action was more effective than Amlodipine therapy in controlling morning BP in hypertensive patients. $^{9}$ In spontaneously hypertensive rats (SHR) treated with $\mathrm{N}$-w-nitro-L-arginine-methylester (LNAME), Cilnidipine dilates afferent and efferent arterioles in the kidney and decrease glomerular capillary pressure, thereby decreasing proteinuria and improving glomerulosclerosis. ${ }^{10}$ In addition a comparative study of Cilnidipine and an ACEI benazepril, has shown that both regimens similarly reduced urine albumin. ${ }^{11}$ Cilnidipine a dual L-and N-type calcium channel blocker may be useful for patients with hypertension and diabetes mellitus from its effects on lipid metabolism and renal function. ${ }^{12}$ Previous reports indicates beneficial effect of Cilnidipine on lipid profile in addition to the antihypertensive activity. ${ }^{13,14}$

\section{METHODS}

Study design: We undertook randomized, open label comparative study of two groups of hypertensive patients in S.K. Medical College and Hospital, Muzaffarpur between May 2012 to October 2012. Total ninety five patients were recruited for this study. One group comprising of 45 patients were taking 5-10mg Amlodipine and other group comprising of 50 patients were taking 10-20 mg Cilnidipine. In Amlodipine group, 15 patients and in Cilnidipine group, 18 patients were diabetic. The numbers of proteinuric patients were 12 and 14 in Amlodipine and Cilnidipine group respectively.

Study procedure: Approval of protocol and study document was taken from institutional ethical committee before study commencement. After taken written informed consent patients were screened for selection criteria. Cilnidipine was administered orally at the dose of $10 \mathrm{mg}$. In 10 patients the magnitude of reduction was insufficient (a difference in $\mathrm{SBP}<20 \mathrm{mmHg}$ or decrease in $\mathrm{DBP}<10 \mathrm{mmHg}$ ). In these patients dose was increased to $20 \mathrm{mg}$ once daily. Amlodipine was administered orally once daily at the dose of $5 \mathrm{mg}$. In 15 patients dose was increased to $10 \mathrm{mg}$ once daily when BP was not successfully controlled. BP and Pulse rate were monitored during morning, daytime and night time and average value is recorded. In proteinuric patients urinary protein content were standardized for urinary excretion of $1 \mathrm{~g}$ creatinine. Values represents the mean of two measurements of each time points during the observation period. Serum concentration of total cholesterol, HDL-C, LDL-C and TG were determined by the enzymatic methods with an autoanalyzer. All DM patients in this study were diagnosed as type 2. Dyslipidemia was defined on the basis of abnormal lipid level (LDLCholesterol(LDL-C) $\geq 140 \mathrm{mg} / \mathrm{dl}$, HDL-Cholesterol(HDLC) $<40 \mathrm{mg} / \mathrm{dl}$, Triglyceride $(\mathrm{TG}) \geq 150 \mathrm{mg} / \mathrm{dl})$.

Statistical Analysis: Values are expressed as the mean \pm SD. The difference of the baseline characteristics and change in BP and PR parameter between the Amlodipine and Cilnidipine groups were compared using an unpaired t-test. The difference between the values before and after antihypertensive medication within the same group were tested using a paired t-test. $\mathrm{P}$ value $<0.05$ considered statistically significant.

\section{RESULTS}

Table 1 summarizes the baseline characteristics of the patients enrolled for this study. There were no significant differences in background factors between the Amlodipine and Cilnidipine groups.

Table 1: Baseline characteristics of hypertensive patients.

\begin{tabular}{|lll|}
\hline & $\begin{array}{l}\text { Amlodipine } \\
(\mathbf{n = 4 0 )}\end{array}$ & $\begin{array}{l}\text { Cilnidipine } \\
(\mathbf{n = 4 5})\end{array}$ \\
\hline Male (\%) & 76 & 64 \\
\hline Age (Years) & $60 \pm 4.7$ & $62 \pm 6.5$ \\
\hline BMI $\left(\mathrm{Kg} / \mathrm{m}^{2}\right)$ & $24 \pm 3$ & $23 \pm 2.6$ \\
\hline Number with diabetes & 15 & 18 \\
\hline Number with Proteinuria & 12 & 14 \\
\hline Day time SBP(mmHg) & $166 \pm 16$ & $166 \pm 11$ \\
\hline Day time DBP(mmHg) & $98 \pm 8.6$ & $100 \pm 10$ \\
\hline Day time PR (bpm) & $76 \pm 9.8$ & $78 \pm 7.2$ \\
\hline Night time SBP(mmHg) & $144 \pm 18$ & $146 \pm 16$ \\
\hline Night time DBP(mmHg) & $94 \pm 6.4$ & $96 \pm 6$ \\
\hline Night time PR(bpm) & $62 \pm 7.2$ & $64 \pm 8.4$ \\
\hline Morning SBP(mmHg) & $164 \pm 16$ & $166 \pm 10$ \\
\hline Morning DBP(mmHg) & $96 \pm 6.6$ & $98 \pm 8$ \\
\hline Morning PR(bpm) & $74 \pm 8.2$ & $76 \pm 9.8$ \\
\hline
\end{tabular}

Table 2: Blood pressure before and after treatment.

\begin{tabular}{|lllllll|}
\hline & \multicolumn{3}{c}{ Amlodipine } & \multicolumn{3}{c|}{ Cilnidipine } \\
\hline & Before & After & P & Before & After & P \\
\hline Day time SBP $(\mathrm{mmHg})$ & $166 \pm 16$ & $152 \pm 11$ & $<0.001$ & $166 \pm 11$ & $154 \pm 11$ & $<0.001$ \\
\hline Day time DBP $(\mathrm{mmHg})$ & $98 \pm 8.6$ & $90 \pm 7.8$ & $<0.001$ & $100 \pm 10$ & $92 \pm 6.8$ & $<0.001$ \\
\hline Night time SBP $(\mathrm{mmHg})$ & $144 \pm 18$ & $132 \pm 13$ & $<0.001$ & $146 \pm 16$ & $138 \pm 14$ & $<0.005$ \\
\hline Night time DBP $(\mathrm{mmHg})$ & $94 \pm 8.4$ & $88 \pm 6$ & $<0.001$ & $96 \pm 10$ & $92 \pm 8$ & $<0.001$ \\
\hline Morning SBP $(\mathrm{mmHg})$ & $164 \pm 16$ & $150 \pm 12$ & $<0.001$ & $166 \pm 12$ & $156 \pm 6$ & $<0.005$ \\
\hline Morning DBP $(\mathrm{mmHg})$ & $96 \pm 6.4$ & $91 \pm 4.4$ & $<0.001$ & $98 \pm 8$ & $94 \pm 6$ & $<0.001$ \\
\hline
\end{tabular}


Daytime, Night time and Morning BP decreased significantly in both groups after treatment. There were no significant differences in the reduction in any of the BP parameters between Amlodipine and Cilnidipine group (Table 2).

Figure 1 shows the effect of Amlodipine and Cilnidipine on the PR levels. In the Amlodipine group, night time PR after treatment was significantly higher than that before treatment and day time PR after treatment tended to be higher than those before treatment. There was significant decrease in day time and night time PR in the Cilnidipine treatment group.

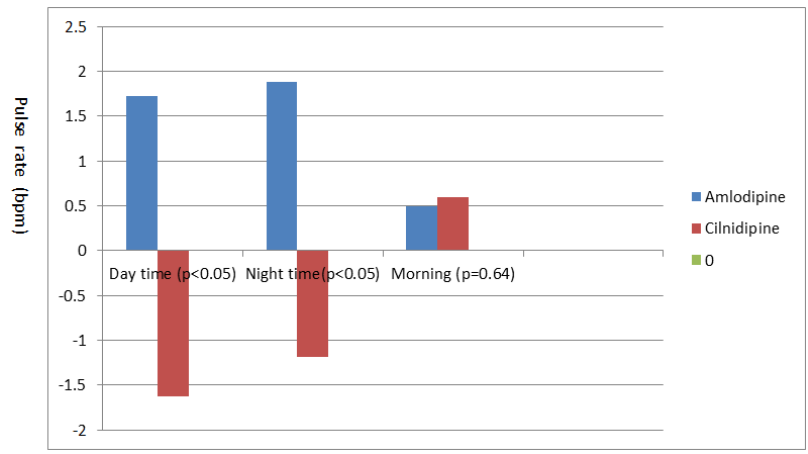

Figure 1: Change in pulse rate (PR) after Amlodipine and Cilnidipine treatment compared to the pretreatment value by paired t-test.

Figure 2 shows the effect of Amlodipine and Cilnidipine on excretion of protein after treatment. The protein/creatinine ratio was significantly lower with Cilnidipine than Amlodipine group.

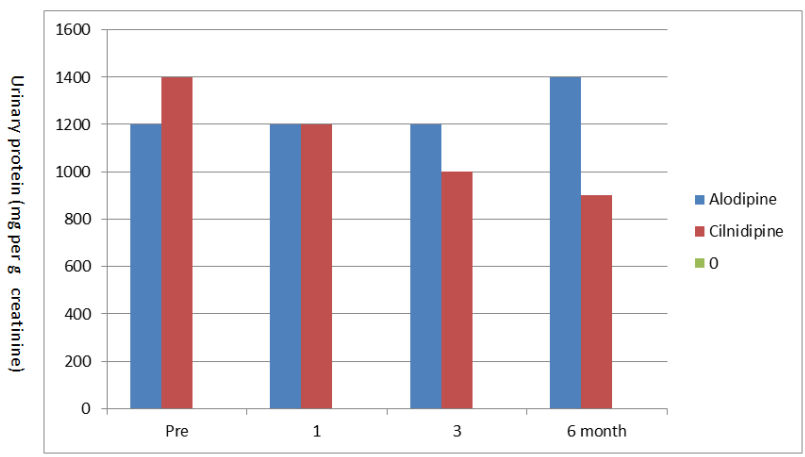

Figure 2: Change in urinary protein/creatinine ratio during the 6 month treatment period in the Amlodipine and Cilnidipine group.

Figure $3 \& 4$ show the effect of Amlodipine and Cilnidipine on lipid metabolism after treatment. There were no significant differences between the Amlodipine treatment and Cilnidipine treatment in terms of total cholesterol, HDL-c and LDL-c level when the analysis was performed on the entire population, the $\mathrm{DM}(+)$ or the DM(-) group. TG was significantly higher with Amlodipine treatment in the $\mathrm{DM}(+)$ group than in the
DM(-) group, while this parameter did not differ significantly with Cilnidipine treatment between the $\mathrm{DM}(+)$ group and the $\mathrm{DM}(-)$ group.

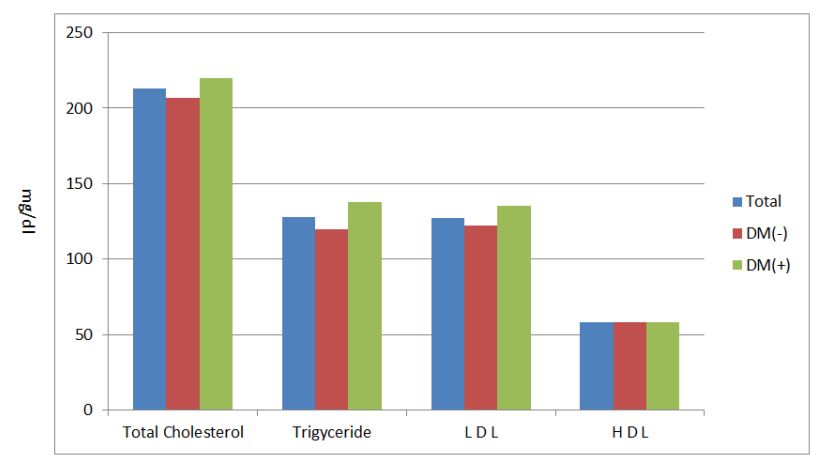

Figure 3: Effect of Amlodipine on lipid metabolism after treatment. $\mathrm{DM}(+)$ Patients with diabetes mellitus, $\mathrm{DM}(-)$ Patients without diabetes mellitus.

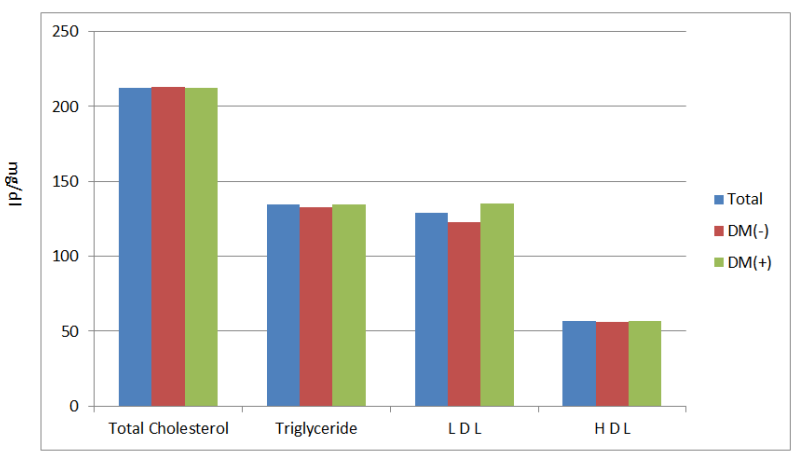

Figure 4: Effect of Cilnidipine on lipid metabolism after treatment. $\mathrm{DM}(+)$ Patients with diabetes mellitus, DM(-) Patients without diabetes mellitus.

\section{DISCUSSION}

Epidemiological studies have demonstrated that a higher heart rate is associated with a long term risk of cardiovascular mortality, independent of other cardiac risk factors. ${ }^{15}$ It has been reported that treatment with short acting calcium antagonist may not prevent cardiovascular disease. ${ }^{16,17}$ Accordingly, long lasting calcium channel blockers that exert less influence on the sympathetic nervous system are now recommended for treatment of hypertension. ${ }^{18} \mathrm{~A}$ recent clinical trial demonstrated that lowering of BP was associated with a significant fall in cardiovascular event. ${ }^{19}$

In this study once daily use of Amlodipine or Cilnidipine significantly reduced the BP. We found that Cilnidipine but not Amlodipine significantly decreased the BP level without causing an increase in PR. There have been previous reports that compared the effects of Amlodipine and Cilnidipine. ${ }^{20,21}$ There was a significant negative correlation between the degree of SBP change and that of PR change after Cilnidipine treatment. This finding is an agreement with several previous studies ${ }^{22,23}$ in which 
Cilnidipine suppressed sympathetic nervous activity, especially under a stress-induced hyperactive condition.

Blood pressure control is important in suppressing the onset of renal dysfunction. ${ }^{24}$ It was reported that antihypertensive therapy suppressed the progression of renal dysfunction. ${ }^{25}$ Regarding glomerular kinetics, it has been shown that inhibition of angiotensin II suppress the elevation of glomerular pressure. Among CCBs, Cilnidipine has been reported to reduce glomerular pressure. $^{26}$ Furthermore, regarding the effect of Cilnidipine and Amlodipine on renal function, Kojima et al, reported that the level of urinary protein elevated after Amlodipine treatment in urinary protein positive hypertensive patients as compared to baseline level, while there was no significant difference in the level of urinary protein before and after Cilnidipine treatment. ${ }^{27}$ Fujita et al conducted a CARTER study involving patients with hypertension and chronic renal disease demonstrating that urinary protein during renin-angiotensin inhibitor therapy was further reduced by concomitant use of Cilnidipine but it was not further reduced by concomitant Amlodipine use. $^{28}$ The result from the present study were identical to those of previous reports. A possible mechanism for the renal protection effects of Cilnidipine, unlikely the other CCBs has been explained as follows. Since L type calcium channels are present primarily on afferent arterioles, the inhibition of these channels causes dilatation of only afferent arterioles, resulting in elevation of glomerular pressure. On the other hand, $\mathrm{N}$ - type calcium channels, which are located in sympathetic nerve endings, control both afferent and efferent arterioles, thus resulting in well-balanced dilatation of both arterioles.

Concerning lipid metabolism, neither total cholesterol, HDL-C nor LDL-C level with Amlodipine differed significantly from those with Cilnidipine in $\mathrm{DM}(+)$ or DM(-) groups. With Amlodipine, TG was significantly higher in $\mathrm{DM}(+)$ group than in $\mathrm{DM}(-)$ group, while no such difference was noted with Cilnidipine. These results indicate that Cilnidipine reduces $\mathrm{TG}$ in hypertensive patients with diabetes mellitus. The results from this study were identical to those of previous reports. ${ }^{29,30}$

Funding: No funding sources

Competing interests: None declared

Ethical approval: The study was approved by the Institutional Ethical Committee

\section{REFERENCES}

1. Dietz JD, Du S, Bolten CW, Payne MA, Xia C, Blinn JR, et al. A number of marketed dihydropyridine calcium channel blockers have mineralocorticoid receptor antagonist activity. Hypertension 2008;51:742-8.

2. Giles TD. Hypertension is taking on a 'new look' Business briefing. US Cardiology 2006:1-4.

3. Fujii S, Kameyama K, Hosono M, Hyashi Y, Kitamure K. Effect of Cilnidipine, a novel dihydropyridine $\mathrm{ca}^{2}$ channel antagonist on N-type $\mathrm{Ca}^{2}$ channel in rat dorsal root ganglion neuron. $\mathrm{J}$ Pharmacol Exp Ther 1997;280:1184-91.

4. Hirning ID, Fox AP, Mc Cleskey FW, et al. Dominant role of N-type $\mathrm{Ca}^{2}$ in evoked release of nor- epinephrine from sympathetic neurons. Science 1998;239:57-61.

5. Minami J, Ishimitsu $T$, Kawano $Y$, Numabe A, Matsuoka H. Comparison of 24-hour blood pressure, heart rate and autonomic nerve activity in hypertensive patients treated with Cilnidipine or Nifedipine retard. J Cardiovasc Pharmacol 1998;32:331-6.

6. Takahara A. Cilnidipine: a new generation $\mathrm{Ca}^{2}+$ channel blocker with inhibitory action on sympathetic neurotransmitter release. Cardiovasc Ther 2009;27:124-39.

7. De Champlain J, Karas $M$, Nguven $P$, et al. Different effect of nifedipine and amlodipine on circulatory catecholamine level in essential hypertensive patients. J Hypertens 1998;16:1357-69.

8. Hoshide S, Kario K, Ishikawa J, et al. Comparison of the effects of Cilnidipine and Amlodipine on ambulatory blood pressure. Hypertens Res 2005;28:1003-8.

9. Yamagishi T. Beneficial effect of Cilnidipine on morning hypertension and white- coat effect in patients with essential hypertension. Hypertens Res 2006;29:339-44.

10. Zhou X, Ono H, Ono Y, Frohlich ED. N- and Ltype calcium channel antagonist improve glomerular dynamics, reserves severe nephrosclerosis and inhibits apoptosis and proliferation in an LNAME/SHR model. J Hypertens 2002;20:993-1000.

11. Rose GW, Konnoy, Ikebukuroh, et al. Cilnidipine is as effective as benazepril for control of blood pressure and proteinuria in hypertensive patients with benign nephrosclerosis. Hypertens Res 2001;24:377-83.

12. Masuda $\mathrm{T}$, Ogura $\mathrm{MN}$, Moriya $\mathrm{T}$, Takahira N, Matsumoto T, et al. Beneficial effects of L- and Ntype calcium channel blocker on glucose and lipid metabolism and renal function in patients with hypertension and type II diabetes mellitus. Cardiovasc Ther 2011;29:46-53.

13. Ahaneka JE, Sakata K, Urano T, et al. Infuence of baseline values on lipids, lipoproteins, and fibrolytic parameters during treatment of hypertension with Cilnidipine. Pharmacol Res 2000;41:79-82.

14. Ahaneku JE, Sakata K, Uranol T, et al. Effects of Cilnidipine on lipids, lipoproteins and fibrinolytic system in hypertensive patients. Drugs Exp Clin Res 2000,26:119-23.

15. Gillman MW, Kannel WB, Belanger A, Agostino RB. Influence of heart rate on mortality among person with hypertension: the Framingham Study. Am Heart J 1993;125:1148-54.

16. Furberg CD, Psaty BM, Meyer JV. Nifedipine: dose-related increase in mortality in patients with 
coronary heart disease. Circulation 1995;92:132631.

17. Psaty BM, Heckbert SR, Koepsell TD, et al. The risk of myocardial infarction associated with antihypertensive drug therapies. JAMA 1995,274:620-5.

18. Chobanian AV, Bakris GL, Black HR, et al: The seventh report of the Joint National Committee on prevention,detection, evaluation and treatment of high Blood Pressure: the JNCI report. JAMA 2003;289:2560-71.

19. ALLHAT Officers and Coordinators for the ALLHAT Collaborative Research Group. Major outcomes in high-risk hypertensive patients randomized to angiotensin-converting enzyme inhibitor or calcium channel blocker vs diuretic: The Antihypertensive and Lipid-Lowering Treatment to Prevent Heart Attack Trial (ALLHAT). JAMA 2002;288:2981-97.

20. Sataka K, Shirotani M, Yoshida H, et al. Effects of Amlodipine and Cilnidipine on cardiac sympathetic nervous system and neuro hormonal status in essential hypertension. Hypertension 1999;33:144752.

21. Minami J, Ishimitsu T, Matsuoka H. Effects of Amlodipine and Nifedipine retard on autonomic nerve activity in hypertensive patients. Clin Exp Pharmacol Physiol 1998;25:572-6.

22. Morimoto S, Takeda K, Oguni A, et al. Reduction of white coat effect by Cilnidipine in essential hypertension. Am J Hypertens 2001;14:1053-7.

23. Razicka M, Leenen FH. Relevance of $24 \mathrm{~h}$ blood pressure profile and sympathetic activity for outcome on short versus long acting 1,4dihydropyridines. Am J Hypertens 1996;9:86-94.
24. Vupputurti S, Batuman V, Bazzano LA. Effect of blood pressure on early decline in kidney function among hypertensive men. Hypertension 2003;42:144-9.

25. Peterson JC, Adler S, Burkart JM, et al. Blood pressure control, proteinuria, and the progression of renal disease. The Modification of Diet in Renal Disease Study. Ann Intern Med 1995;123:754-62.

26. Zhou X, Ono H, Ono Y, Frohlich ED. N-and L-type calcium channel antagonist improve glomerular dynamics, reverse severe nephrosclerosis and inhibits apoptosis and proliferation in an LNAME/SHR model. J Hypertens 2002;20:993-1000.

27. Kojima S, Shida M, Yokoyana H. Comparison between Cilnidipine and Amlodipine besilate with respect to proteinuria in hypertensive patients with renal diseases. Hypertens Res 2004;27:379-85.

28. Fujita T, Ando K, Nishimura H, Ideura T, Yasuda G, Takahashashi K. Antiproteinuric effect of the calcium channel blocker Cilnidipine added to rennin angiotensin inhibition in hypertensive patients with chronic renal disease. Kidney Int 2007;72:1543-9.

29. Masuda T, Ogura MN, Moriya T, Takahira N, Matsumoto T, et al. Beneficial effects of L- and Ntype calcium channel blocker on glucose and lipid metabolism and renal function in patients with hypertension and type II diabetes mellitus. Cardiovasc Ther 2011;29:46-53.

30. Ahaneku JE, Sakata K, Uranol T, et al. Effects of Cilnidipine on lipids, lipoproteins and fibrinolytic system in hypertensive patients. Drugs Exp Clin Res 2000;26:119-23.

doi:10.5455/2319-2003.ijbcp20130308

Cite this article as: Zaman ZA, Kumari V.

Comparison of the effects of amlodipine and cilnidipine on blood pressure, heart rate, proteinuria and lipid profile in hypertensive patients. Int J Basic Clin Pharmacol 2013;2:160-4. 